\title{
A TIME-DEPENDENT MODEL OF AN ICE DOME-ICE STREAM-ICE SHELF SYSTEM: PRELIMINARY RESULTS
}

\section{(Abstract only)}

by

\author{
Robert Bindschadler \\ (Goddard Laboratory for Atmospheric Sciences, NASA/Goddard Space Flight Center, Greenbelt, \\ Maryland 20771, U.S.A.) \\ and Robert Gore \\ (General Electric Corporation, Lanham Center Operations, 4701 Forbes Boulevard, Lanham, \\ Maryland 20706, U.S.A.)
}

\section{ABSTRACT}

This model is designed to simulate the temporal response of an ice sheet along a flow line by accounting properly for the division of the driving stress into basal-stress and longitudinal-stress gradient components. A vertical section along a central flow line is divided into both horizontal and vertical grid points. A self-consistent solution of stress and velocity is found for any specified geometry. The sliding velocity is determined from a relationship which includes the base stress and a prescribed sub- glacial water pressure. In these experiments, the ice is assumed to be isothermal. For any given set of initial conditions and a specified mass-balance distribution, the model follows the temporal behavior of the flow line to a steady state. In later work, the water pressure will be calculated from the equilibrium pressure within Röthlisberger conduits for the specific geometry and determined rate of meltwater production. The time-varying temperature field due to conductive and advective processes will be included in later versions of the model.

\section{ANALYSIS OF INTERANNUAL CHANGES IN} ANTARCTIC SEA-ICE COVER USING PASSIVE

\section{MICROWAVE OBSERVATIONS (Abstract only)}

\section{H. J. Zwally, J. C. Comiso, C. L. Parkinson and F. D. Carsey,} (Goddard Laboratory for Atmospheric Sciences, NASA/Goddard Space Flight Center, Greenbelt, Maryland 20771, U.S.A.)

\section{W. J. Campbell}

(US Geological Survey, University of Puget Sound, Tacoma, Washington 98416, U.S.A.)

\section{and P. Gloersen}

(Goddard Laboratory for Atmospheric Sciences, NASA/Goddard Space Flight Center. Greenbelt, Maryland 20771, U.S.A.)

\section{ABSTRACT}

A quantitative comparison of seasonal and interannual Antarctic sea-ice coverage over the four years 1973-76 has been accomplished through the use of passive microwave imagery from the Nimbus-5 satellite. For the entire Southern Ocean both the total ice extent (area with ice concentration greater than 15\%) and the actual ice area (the spatially-integrated ice concentration) have decreased over this period of $4 \mathrm{a}$, but not uniformly in a11 regions. From 1973 to 1976 the annual-mean value of total ice extent decreased from $13.8 \times 10^{6} \mathrm{~km}^{2}$ to $12.1 \times 10^{6} \mathrm{~km}^{2}$, yielding an average decrease of $4.0 \% \mathrm{a}^{-1}$. The inter-annual difference is greatest during the spring, as the ice decays, with the decrease in the December-mean averaging $8.4 \% \mathrm{a}^{-1}$, the largest of any month. The decrease in the November-mean averaged $4.5 \% \mathrm{a}^{-1}$. The overall decrease was principally due to the consistent yearly decrease of ice in the Weddell Sea sector $\left(60^{\circ} \mathrm{W}\right.$ to $\left.20^{\circ} \mathrm{E}\right)$. O ther sectors show less consistency. For instance, the ice in the Ross Sea sector $\left(130^{\circ} \mathrm{W}\right.$ to $160^{\circ} \mathrm{E}$ ) increased from 1973 to 1974 and then decreased from 1974 to 1976 , and no consistent trend is apparent in the ice extent between $20^{\circ} \mathrm{E}$ and $160^{\circ} \mathrm{E}$. The total ice extent in the BellingshausenAmundsen seas sector $\left(60^{\circ} \mathrm{W}\right.$ to $\left.130^{\circ} \mathrm{W}\right)$ actually increased slightly from 1973 to 1976 . The area of the open water within the ice pack behaved differently from the total ice area, increasing each year from February to November but having no clear interannual trend. A detailed analysis of the passive microwave imagery for the Antarctic region is planned for publication in an atlas. 